\section{Military Technical College Kobry El-Kobbah, Cairo, Egypt}

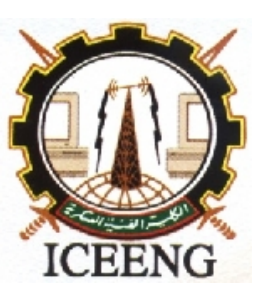

\section{$7^{\text {th }}$ International Conference on Electrical Engineering \\ ICEENG 2010}

\title{
10-Criteria for E-Learning Interface Design: Theoretical Study
}

\author{
By \\ Diaa Z. Shollar* \\ Maha A. Hana* \\ Said A. Elgaber *
}

\section{Abstract:}

Recently the number of learning management systems (LMS) in educational institutions and companies is growing up; researches for evaluating the functionalities of these systems have published a lot. This paper addresses the problem of creating e-learning interface designs that are both effective and usable. It focuses on this challenge by proposing 10-criteria for e-learning interface design (10-CELID). 10-CELID provides a guide for e-learning interface designers to design effective and usable interfaces. 10CELID are Visual design, Content Quality, Accessibility, Ease of use, Efficiency, Functionality, Understandability, Navigation, Motivation and Satisfaction.

\section{Keywords:}

Interface design, Criteria, e-learning

* Faculty of Computers and Information, Helwan Univesity, Cairo, Egypt 


\section{Introduction:}

Lately with the rapid increase of ICT infrastructures, every educational institution has the opportunity to make use of the Internet as a communication medium with its learners. The concepts and methodologies of technology-based learning enable effective and efficient access to learning materials especially with e-learning [1]. E-learning changes the teaching strategies in schools and universities, the learning strategies and employees training strategies in businesses [2].

The advantages of e-learning compared to traditional learning are instantly evident with e-learning making education independent of time and location. More importantly, it opens up fresh possibilities for implementing pedagogical innovations in an environment where learners are expected to function as active, independent, selfreflected and collaborative participants. In addition, e-learning assists teachers in the management of online courses, allowing them to create, add, modify, customize, and reuse digital content and learning objects [3].

The consequence to the advancements of web-based technologies is the development of powerful software systems, known as learning management systems (LMS), in order to enhance learning in a variety of environments [4]. Essentially, an LMS provides an automated mechanism for delivering course content and tracking learner progress. Learning management systems allow learners to view multimedia lectures, communicate with their teachers and each other in learning communities, download course materials, take online quizzes and submit homework and class work assignments. In addition, these systems are used to improve the internal faculty organization [3].

When evaluating the user interface, Brandon (1997) identified the following issues: "Is the course intuitive to use, such that the learner needs little or no explanation to proceed through the course? Is the overall screen design consistent, consolidated, clean and clear? Are the graphics appealing and understandable?" [5] Elaborates on those issues that considering them helps to ensure that the interface design is effective and user friendly.

In fact, usability of e-learning designs is directly related to their pedagogical value. Jakob Nielsen brought the concept of web usability by stating that making web pages simple to navigate and intuitively organized; helps the users find the information easily [3]. [6] Stated that usability of e-learning application is not enough to achieve the pedagogical goals. Accordingly, some previous studies focused on e-learning usability while others focused on the e-learning effectiveness. In our opinion, neither one is sufficient by itself but a merge is a better solution.

The focus of this paper is to select and propose an organized set of criteria to design effective and usable e-learning interfaces. The beneficiaries of this work are the elearning system designers who should follow those guidelines. In addition to the instructors and the learners who utilize e-learning materials. 
This paper is organized as follows; section two illustrates previous interface design criteria. Section three proposes a theoretical model for e-learning interface design criteria. Section 4 concludes the proposed model and elaborates future work.

\section{Related Work:}

Researchers spend a lot of effort trying to find out what are the best criteria for interface design [7]. Design criteria referred to criteria that designers should meet in designing some system or device [8]. There are several researches on design principles [9], heuristics [3] and criteria [10]. Their assumption is that when the guidelines are appropriately applied, they have a positive effect on the overall usability.

[11] Develop an organized set of design criteria for evaluating learning web sites. These criteria are categorized into three levels. The first level is content which contains credibility, clearness, currency and both accuracy and coverage as factors. The second level is the instructional design which contains objectives, practice, and feedback as factors. The last level is interface design which contains layout, consistency, information organization, navigation, and visual appeal as factors. Sam Joachim [12] proposed the same categories with almost the same criteria, but he replaced interface design level into usability and added learner support factor to this level.

[13] Propose four general areas to evaluate effectiveness of online learning materials. The first general area is usability with response time, navigation, scannability, and accessibility as factors. The second one is the use of multimedia by combining text, sounds, images, animation, and/or video effectively. The next one is effective design of practice exercises where (the quantity and quality of practice is a key feature of elearning. The last one is effective use of collaboration among learners and learners with instructors.

[14] Develop a model for measuring e-learner satisfaction including four main criteria. The first criterion is learner interface that is characterized by user-friendly, stable, easy to use, understand and easy to find the needed content. The second one is learning community that enables to discuss questions with teachers and other learners and to share content. The third one is up-to-date, sufficient, useful, and appropriate content. The last one is personalization that enables learners to choose what they want to learn and to control their learning progress.

[6] Develop a conceptual framework that combines web and instructional design parameters and associates them with the most prominent affective learning dimension, which is an intrinsic motivation. This framework included the following criteria: content, support, visual design, navigation, accessibility, interactivity, learnability, and motivation.

DeLone and McLean [15] presented IS success model which is shown in figure 1. This model includes constructs such as system quality (performance of the IS in terms of 
reliability, convenience, ease of use, functionality, and other system metrics), information quality (Characteristics of the output offered by the IS, such as accuracy, timeliness, and completeness), user satisfaction (approval or likeability of an IS and its output), etc.

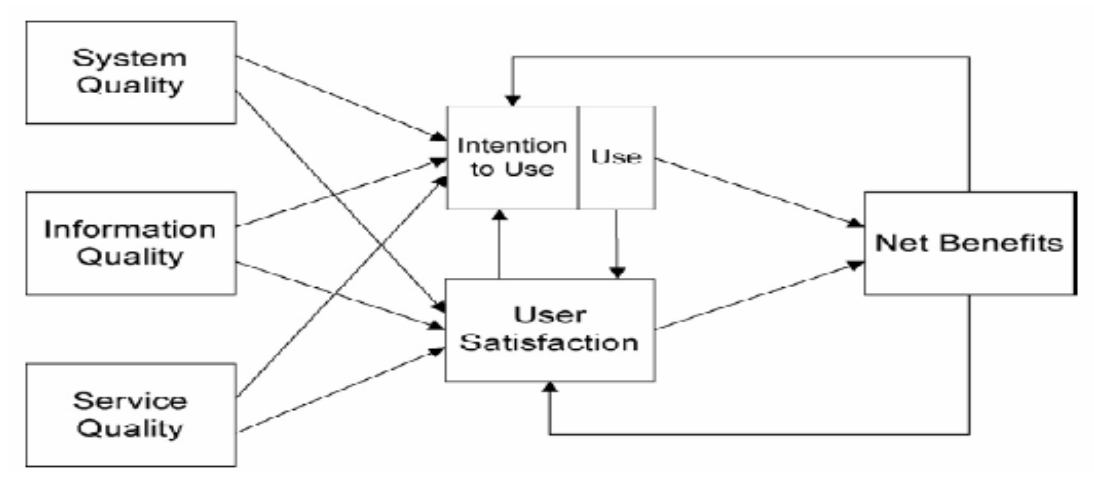

Figure (1): DeLone and McLean IS success model

In 2009, the e-Learning Courseware Certification Program (eLCC) quality evaluation aimed to recognize and promote well-designed and self-paced e-learning courseware through examining the educational quality of e-learning courseware from four quality aspects. The first aspect is providing learners with accurate, appropriately organized, clearly expressed content. The second one is to provide navigational tools. The next aspect is instructional design with content objectives, instructional presentation, adequately designed practice, feedback and assessment. The last one is providing instructional media to sustain motivation for learning [16]. Cheng-Mei Hsu et al [17] proposed objective design criteria for web-based learning platforms. They added some criteria to those of eLCC such as content evaluation, help and assistance provision, the appropriateness of learning material, and the clearness of text.

\section{10-Criteria for E-Learning Interface Design (10-CELID):}

An effective teaching or learning through an e-learning system depends on many factors or criteria [18]. A theoretical model of e-learning interface design criteria is proposed in this section and summarized in figure 2. A 10-criteria model helps developers of elearning systems to design effective and usable interfaces for learning materials. These criteria are classified and organized into the following categories and sub categories: 


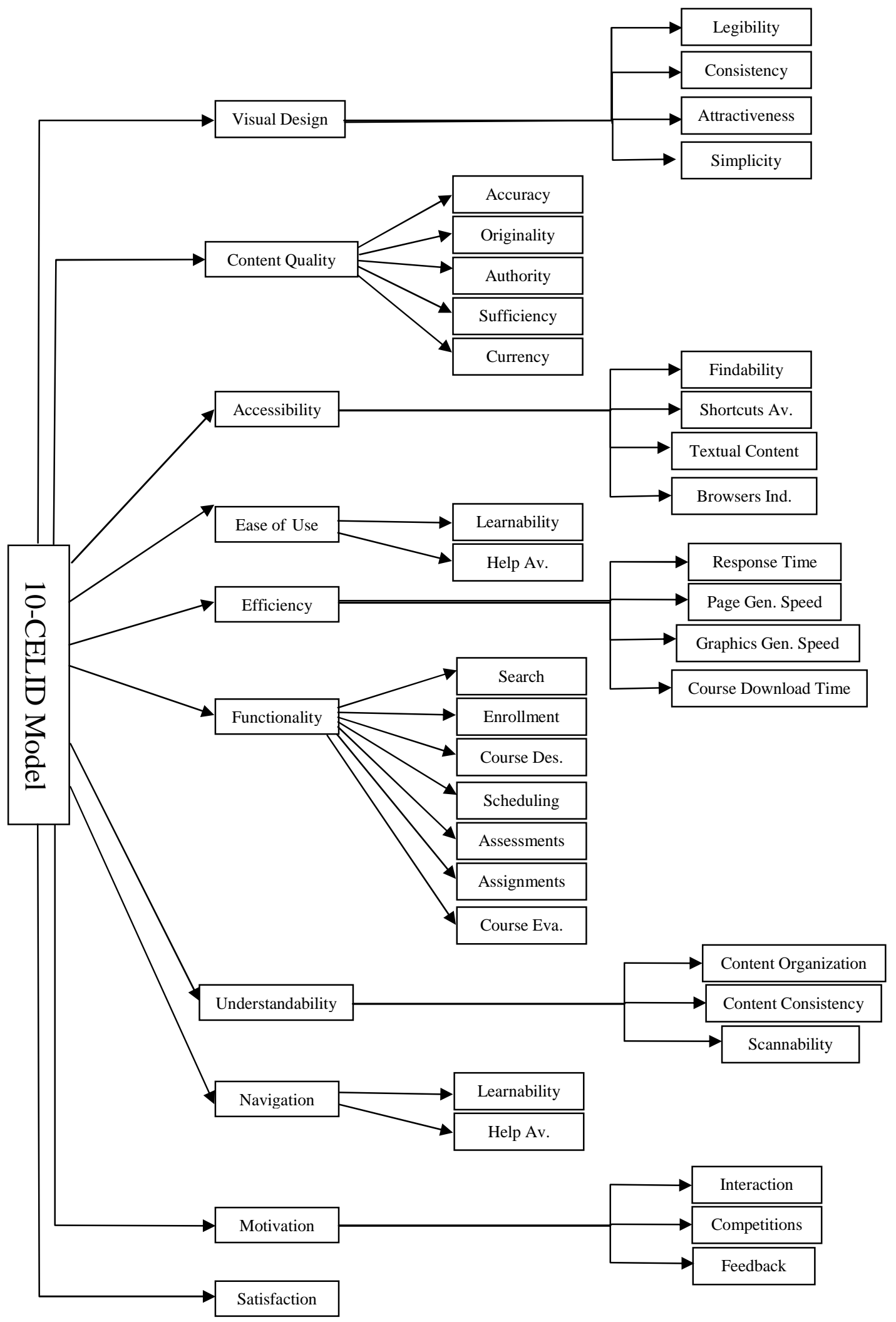

Figure (2): 10-CELID Model 


\subsection{Visual Design}

Users judge e-learning systems on more than courses and content. Most learners make their decisions within seconds of seeing the design of the first page of the course. Opinion based on content and site features comes only after visual judgments. The overall appearance should be professional to engage learners. The design should make all needed options and materials for a given task visible without distracting the user with extraneous or redundant information. Visual design is important as it sends the message of the e-learning application. Visual design encompasses anything with visual characteristics such as: color, fonts, images, graphics, and layout $[19,20]$. The visual design has four dimensions which are: legibility, consistency, attractiveness, and simplicity.

\section{- Legibility}

Legibility means that text is easily read. A display's legibility is critical and necessary for designing a usable interface. The designer should be able to determine a comfortable font style. High figure-ground contrast between text and background increases legibility. Dark text against a light background is the most legible $[19,20,21]$.

\section{- Consistency}

Consistency is creating a sense of interface layout and primary elements which are in a harmony within the LMS [19]. Consistency also means that the behavior of interface controls such as buttons, lists, and menu items are not changed within or among pages. Using the same or similar colors, fonts, and backgrounds for similar information enforces consistency [22,23].

\section{- Attractiveness}

Design success depends on attractiveness or visual appeal. Attractiveness means that the interface is pleasing to the eye and users enjoy and become engaged in the e-learning application. The visual appeal of courses helps in determining an e-learning initiative's success. Beautiful and attractive visuals can encourage learners to stick around a little longer [19].

\section{- Simplicity}


The visual design is preferred to be simple. Simple design means clear and uncluttered one. Crowded interfaces are difficult to understand and, hence, are difficult to impress the learner [22].

\subsection{Content Quality}

Content is essentially the material used to convey the subject matter. It is expressed via text, graphics, audio, and other form of interaction [24]. In a report on the effectiveness of web-based instruction, [5] suggested that the quality of course content is the most important factor that determines the effectiveness of e-learning. Content quality is a multi-dimensional concept that covers six dimensions which are: accuracy, originality, authority, sufficiency, currency, and proper printing.

\section{- Accuracy}

The purpose of accuracy is to guarantee that the content is actually correct, factual, and exact. The language of the course content must be correct, clear and unambiguous both syntactically and semantically in order to be truly useful [20]. Some sources present factual material and others only represent the author's opinion. If the content is presented as fact, reference to verify the accuracy of the content should be available. While if it is an author's opinion, it may not be accurate because it may be biased or promote a particular point of view $[11,25]$. Accuracy of available courses on the LMS is the responsibility of the author.

\section{- Originality}

Originality means that the sources and references of the content is clearly stated, whether original or borrowed, quoted, or imported. For learning interfaces, sources are given for the course, or links are provided to related sources of content to support effective learning. So, learners can verify and may understand the course through the original sources [21].

\section{- Authority}

Knowing who created the content of the course and providing information about the author's experience/education determines whether the content is credible or not. Author's contact information is clearly presented to provide communication means with the author easily $[25,26]$. 


\section{- Sufficiency}

Sufficiency means that learners are provided the learning material in breadth and depth in order to enable them to understand and meet the learning objectives [10,25,27].

\section{- Currency}

Currency is to keep the content up-to-date. Nothing frustrates a user and limits his continuity with e-learning courses more than finding that the content is out of date [25].

\subsection{Accessibility}

Accessibility refers to provide access for all users regardless of their physical abilities. E-courses should be designed and provided in different ways such as text, audio, and/or video. This helps normal learners and those with disabilities to access the learning materials easily. [10,19,20,28,29]. Accessibility has four dimensions which are: findability, shortcuts availability, textual content option for multimedia content, and browsers independence.

\section{- Findability}

Findability means that learners are able to find needed content quickly and easily throughout the online course, whether it is long or short, abstract or detailed, and theoretical or practical [19].

\section{- Shortcuts Availability}

Some learners cannot manipulate a mouse or prefer using keyboard shortcuts than using the mouse. Therefore, keyboard shortcuts are generally employed to allow access to the most common commands easily. [28].

\section{- Textual Content Option for Multimedia Content}

A text equivalent for every non-text element is provided. Every image, Java applet, Flash file, video file, or audio file that conveys content has an equivalent text-only version. This enables all learners especially visually impaired and those with slow dial-up connections at home to view all of the e-course units in high contrast text-only and without graphics and pictures $[19,29,30]$. 


\section{- Browsers Independence}

Pages should be checked for compatibility on a range of browsers and screen resolutions [28].

\subsection{Ease of Use}

The interface should be easy to use for all learners especially those of a little experience of using computers, Internet, and LMS. Easy use of e-courses is an important criterion to facilitate learners in finding what they are looking for and in helping them concentrate on their main learning goal. This can motivate them to reuse the application [10]. Ease of use criterion has two dimensions which are: learnability and help availability.

\section{- Learnability}

Learnability refers to how fast a learner who has never seen the user interface before acquires all the functionality of the interface [31]. Easy to learn user interface does not mean that no instruction is required, but that it is minimal and that learners can pick it up quickly and easily [32].

\section{- Help Availability}

Help tools refer to help learners use a LMS effectively with a minimum number of errors. Some ways to minimize user errors and reduce the cost of mistakes and misuse may include: help menus, search menus and Frequently-Asked Questions [33]. Moreover, help may be represented in different forms such as images, videos, audios, or wizards.

\subsection{Efficiency}

Efficiency is the capability of the software product to provide appropriate performance, relative to the amount of resources used, under stated conditions [33]. Fast access to the content must be examined to ensure that learners requirements are continuously met [34]. Response time, page and graphics generation speed, and course download time are dimensions of efficiency:

- Response Time

Response time from one page to another is preferred to be less than 1 second. Response time of less than 10 seconds keeps within the limit of typical attention 
span; beyond 11 seconds, the user loses the feeling of direct contact [35].

\section{- Page Generation Speed}

Page generation speed must be high enough to satisfy learners' demands. Every page in the course should be loaded in a reasonable time. If not, learners should informed of the expected time for completion $[21,23,28]$.

\section{- Graphics Generation Speed}

Graphics generation speed must be high enough to satisfy learners' demands. It is high when presenting a reasonable amount of small size and good quality graphics [28].

\section{- Course Download Time}

Course download time must be kept to a minimum for learners with dial-up connections. If the load time is too long, learners may get frustrated and bored with the process and did not wait for the course to load [36]. A valuable option is to continue download if interruptions occur.

\subsection{Functionality}

Functionality refers to a set of functions that are provided to meet the stated and required needs [2, 29]. Search, enrollment, course description, scheduling, assessments, assignments, and course evaluation are some dimensions of e-learning environment functionality that are required to help learners utilize this environment effectively.

- Search

Search allows learners to rapidly look for a topic of interest in any or all of the e-courses and to easily retrieve the content they require.

\section{- Enrollment}

Course enrollment allows learners to enroll in a specific course. The enrollment checks if all prerequisites are satisfied [29].

\section{- Assessments}

Assessments evaluate learner acquired knowledge according to the learning 
objectives. Successful results of assessments ensure that the learning has actually taken place. Online drill or practice tests can be used to reinforce learning $[10,37]$.

- Assignments

Assignments and exercises are included in learning materials to ensure that learners practice all learning objectives [10].

- Scheduling

Scheduling means providing announced for learners, instructors, courses, and classrooms [29].

\section{- Course Description}

Every course must have a description which includes at least the following: the purpose of the course, target audience, prerequisites, learning objectives, structure of the course, estimated study time, technology and skills requirements, features of delivery and learner support [10,37].

\section{- Course Evaluation}

The main goal of course evaluation is to improve the learning environment. Course evaluation is beneficial because instructors can review how others interpret the learning environment strengths and weaknesses. Therefore enhancing the weak points improves the learning environment [38].

\subsection{Understandability}

An easily understandable e-learning interface helps learners to perform the correct operations. The better learners understand an interface, the more effectively they can use it, and the better they utilize the available functionality [29,39]. Content organization, content consistency, and scannability are dimensions of understandability criterion.

\section{- Content Organization}

It is important to ensure that the content of the course is clearly organized. Content should be organized in a logical way that makes a course easy to read. Interfaces should be neither too busy nor too stark. Chunking is a useful strategy 
that involves breaking the course into units that can be organized into meaningful order or hierarchy $[22,23,29,40]$.

\section{- Content Consistency}

Content consistency means that the content of the course is in the same logical, visual, or physical form throughout the LMS. Consistency enables learners to more quickly build a mental model of a course and to understand how to find content [41].

\section{- Scannability}

Learners tend to scan until they find something interesting and then they focus on it. The ability to skim the e-course allows learners to find their piece of information by scanning rather than reading $[23,40,42]$.

\subsection{Navigation}

Navigation encompasses the range of ways a learner may move around an e-course, and the tools designers offer to help them. A LMS's navigational scheme and features allow learners to find and access information effectively and efficiently $[10,20,28,29]$. Navigation criterion has two dimensions which are: navigation consistency and navigation tools availability.

\section{- Navigation Consistency}

Locating navigational tools in the same place on each page of the course leads to a quick understanding of the navigation's function $[19,28]$.

\section{- Navigation Tools Availability}

Learners should be offered various ways to find information and to move around a course such as a tree of available courses, list of topics, search functions, help, clearly labeled sections, page numbers, etc. The learner must be able to move forward/backward through the learning material and easily indicate location $[19,43]$.

\subsection{Motivation}

In order for the learning to be effective, offering motivational strategies for learners keeps them engaged in the e-learning material. Providing dimensions such as 
interaction, competitions, and feedback is important to improve learners' motivation.

- Interaction

Asynchronous communication technologies (such as a bulletin board and email) and synchronous communication facilities (such as chat sessions and discussion boards) are used in e-learning to engage learners in the exchange of ideas or information. Sharing thoughts and explaining learning matter to other learners is motivating and important. Interaction between instructor and learners can assist them with their learning through providing appropriate support during their online studies for enhancing their learning and enabling them understand their courses $[20,44]$.

\section{- Competitions}

Learners need a competence framework in e-learning application to keep them engaged and motivated. A competence framework in e-learning can be included through assessment component.

\section{- Feedback}

Feedback is particularly important to the effective delivery of e-learning courses [5]. Feedback is information the learners receive from the LMS as the result of their actions. Adequate feedback on learners' assignments and questions is important and constructive to evaluate their studies. Giving learners feedback when they take assessments is a valuable way to help them know if their answers are correct or incorrect [11,19,22,29].

\subsection{Satisfaction}

Learner satisfaction has been found to be an important component in the effectiveness of e-learning systems [5]. Satisfaction encourages learners to continue using the LMS. Satisfaction tells whether learners are happy or not, when they used the LMS, how likely they are to return, whether they will recommend it to others, and much more [20,33].

\section{Conclusions and Future Work:}

Some previous studies focused on usability issues while others concentrated on e- 
learning effectiveness. This paper addressed this challenge by developing the 10-criteria model for e-learning interface design. These criteria are selected carefully from previous work. Developers and instructional designers who follow these criteria are able to guarantee the effectiveness and usability of e-learning interfaces.

10-CELID proposes ten valuable criteria. The first criterion, visual design, is important because learners become engaged in the legible, consistent, attractive, and simple e-learning interface. Then, it emphasizes that the content quality is the most important criterion which determines the effectiveness of e-learning. Accuracy, originality, authority, sufficiency, and currency assure the content quality. In addition, keeping the content organized, consistent, and scannable allows learners to find the needed information quickly and easily.

Providing options such as findability, shortcuts, textual content, and browsers independency are necessary to overcome the challenge of accessibility. Learners need to be offered different navigational tools to move around the learning material easily. Presenting a set of appropriate functions such as search, help, assessments, assignments, and course evaluation is useful in order to meet learners' needs, but easy to learn and use these functions is more valuable.

Efficiency is the most important criterion that determines e-learning usability because efficient e-learning interface satisfies learners' demands. Along with these criteria, offering motivational strategies such as interaction, competitions, and feedback keeps learners engaged in the learning material.

As a result, these criteria if appropriately applied, they are highly expected to have a positive effect on the learners' satisfaction. Authors of this paper intend to apply 10CELID on a sample of e-learning users in different e-learning courses to evaluate effectiveness and usability of e-learning environment. In addition, they will analyze the relationships of the proposed criteria and study the impact of these criteria on both elearning effectiveness and usability.

\section{References:}

[1] Waterhouse S., The Power of E-learning: The Essential Guide for Teaching in the Digital Age, Boston, Pearson, 2005.

[2] Ali A. Alraouf, The Impact of ELearning on Contemporary Architectural Education: A New Paradigmatic Trend, First International Conference of the eLearning: A New Era In Learning \& Culture, University of Bahrain, Kingdom of Bahrain, April 1719, 2006.

[3] Gorgi Kakasevski, Martin Mihajlov, Sime Arsenovski and Slavcho Chungurski, Evaluating Usability in Learning Management System Moodle, 30th Int. Conf. on Information Technology Interfaces, Cavtat, Croatia, June 23-26 2008. 
[4] Brusilovsky, P, A Distributed Architecture for Adaptive and Intelligent L.M.S., AIED 2003.

[5] Tim L. Wentling, Consuelo Waight, James Gallaher, Jason La Fleur, Christine Wang and Alaina Kanfer, e-learning - A Review of Literature, NCSA, 2000.

[6] Panagiotis Zaharias, Developing a Usability Evaluation Method for E-learning Applications: From Functional Usability to Motivation to Learn, Athens University of Economics and Business, 2006.

[7] Martijn van Welie, TASK-BASED USER INTERFACE DESIGN, 2001.

[8] http://www.wordreference.com/definition/design_criteria

[9] Charles Graham, Kursat Cagiltay, Joni Craner, Byung-Ro Lim and Thomas M. Duffy, Teaching in a Web Based Distance Learning Environment: An Evaluation Summary Based on Four Courses, Center for Research on Learning and Technology, Indiana University, 2000.

[10] European Centre of Excellence for e-Learning, http://www.buenaspracticaselearning.com/proyectos-europeos-european-centre-excellence-for-e-learning-e3

[11] Ana Paula Correia and Paulo Dias, Criteria for Evaluating Learning Web Sites: How Does This Impact the Design of e-Learning?, 2001.

[12] Sam Joachim, Criteria of good e-learning material or How we can support quality in e-learning, Institute of Informatics, Humboldt University - Berlin, Germany, 2005.

[13] Michael J. Powers, Effective Online Learning: Recognizing E-Learnability, PAACE Journal of Lifelong Learning, 2005.

[14] Daniel Y. Shee and Yi-Shun Wang, Multi-criteria evaluation of the web-based elearning system: A methodology based on learner satisfaction and its applications, Elsevier, 2006.

[15] Stacie Petter and Ephraim R. McLean, A meta-analytic assessment of the DeLone and McLean IS success model: An examination of IS success at the individual level, Elsevier, 2009.

[16] Chen, M. P., An Evaluation of the ELNP e-Learning Quality Assurance Program: Perspectives of Gap Analysis and Innovation Diffusion, Educational Technology \& Society, 12 (1), 18-33, 2009.

[17] Cheng-Mei Hsu, Yu-Chu Yeh and Jen Yen, Development of design criteria and evaluation scale for web-based learning platforms, International Journal of Industrial Ergonomics, 2009.

[18] Chao, R.-J., \& Chen, Y. H, Evaluation of the criteria and effectiveness of distance e-learning with consistent fuzzy preference relations, Expert Systems with Applications, 2009.

[19] Penny McIntire, Visual Design for the Modern Web, New Riders 2008.

[20] Katz-Haas, Usability Techniques, User-Centered Design and Web Development, 1998. http://www.stcsig.org/usability/topics/articles/ucd_web_devel.html\#visual_design 
[21] Tommy Martin, Web Design Criteria.

[22] Scott W. Ambler, User Interface Design Tips, Techniques, and Principles.

[23] Patricia A. Chalmers, The effects of usability guidelines on web site user emotions, Air Force Research Laboratory, USA, 2005.

[24] Michael Brennan, Susan Funke and Cushing Anderson, The Learning Content Management System A New eLearning Market Segment Emerges, An IDC White Paper, 2001.

[25] Miriam J. Metzger, Andrew J. Flanagin, and Lara Zwarun, College student Web use, perceptions of information credibility, and verification behavior, Elsevier Ltd, 2003.

[26] http://library.csus.edu/services/inst/ICCS/infocomp/tutorials/module5/ web/reliability/index.htm

[27] http://libraries.cuny.edu/iltutorial/05_evaluate/WIA2.html

[28] Adriano Bessa Albuquerque and Arnaldo Dias Belchior: E-Commerce Websites: a Qualitative Evaluation.

[29] L. Olsina, D. Godoy, G.J. Lafuente and G. Rossi, Specifying Quality Characteristics and Attributes for Websites.

[30] A Learning Framework for Information Literacy and Library Instruction programs at Rutgers University Libraries.

[31] http://www.doublespark.co.uk/blog/usability-components-learnability-and-usability/

[32] http://cfg.cit.cornell.edu/design/concepts.html

[33] Tailoring the 9126 Quality Model. http://www.cs.uccs.edu/ chamillard/cs536/Papers/9126Handout.pdf

[34] STEPHANOS MAVROMOUSTAKOS, KATERINA PAPANIKOLAOU, ANDREAS S. ANDREOU and GEORGE A. PAPADOPOULOS, Human and Technological Issues in The E-Learning Engineering Process.

[35] http://www.ariadneproject.org/index.php?id=63

[36] http://class.unl.edu/design/id2e.html

[37] Allen Quesada Pacheco, Web-based Learning (WBL): A Challenge For Foreign Language Teachers, 2005.

[38] http://en.wikipedia.org/wiki/Course_evaluation

[39] http://www.sapdesignguild.org/resources/simplification/Principles/Understand.htm

[40] http://en.wikipedia.org/wiki/User-centered_design

[41] The Golden Rules of User Interface Design, John Wiley \& Sons, 1997.

[42] http://en.wikipedia.org/wiki/Technical_writing_for_the_Web\#Consistency

[43] http://oa.mo.gov/itsd/cio/architecture/domains/interface/CC-Navigation072205.pdf

[44] Christian J. Eibl and Sigrid E. Schubert, Development of E-Learning Design Criteria with Secure Realization Concepts, Springer-Verlag Berlin Heidelberg, 2008. 